\title{
Evaluating marine safety factors and their relationship to diving accidents and diseases
}

\author{
Prof. Dr. Wael Mohamed Mohamed omar / Mohamed Yousef Mohamed ElBaradie
}

Prof. and Head of the Department of Health and Biomedical Sport-Sciences /PHD

Researcher in water sports training, diving division, Faculty of Physical Education for Boys, Alexandria University.

\begin{abstract}
Research Objectives: This research aims at Evaluating marine safety factors and their relationship to diving accidents and diseases along with identify the following:

1- Knowing the diving accidents, diseases and injuries prevailing in the Arab Republic of Egypt and limiting their spread and prevention.2-Learn about the causes of diving accidents, diseases and injuries and work to avoid them. 3- Defining the scientific methods and means to avoid diving accidents, diseases and injuries.4- Setting scientific standards to improve marine health and the safety of divers.5- Learn about diving accidents and diseases spread in Australia, the leader in diving. Research Methodology: Data was collected through questionnaires and personal interviews with experts in the field of diving, a sample of professional divers, divers working in the field of commercial diving, divers working in the field of recreational diving, and students of diving specialization in the Faculty of Physical Education for Boys, University of Alexandria.

Research Sample: Research Sample consisted of 150 recreational, commercial and professional diver and diving training students at the Faculty of Physical Education, Alexandria University, were randomly selected to answer the questionnaire. Conclusions: In light of the research objectives, hypotheses, the nature of its variables and the results of statistical treatments, the researcher has been able to reach the following conclusions: 1- It was found that the most common diseases, accidents and injuries related to diving are (nitrogen narcosis), (damage to an eardrum), (wounds), (inhalation of salty water), (injury to the teeth due to pressure), (damage to injury in the body's spaces such as sinuses Nasal), (disorientation during diving), (injury caused by pressure in the blood vessels around the eye) [The percentages were, respectively, 17\%, 13\%, 13\%, 11\%, 6\%, $6 \%, 6 \%, 5 \% .2$ - The reasons for the occurrence of many diving injuries and accidents that were addressed in the study were identified, and the knowledge of how to prevent and treat them and reduce their incidence rates was determined.3- The diving centers do not fully apply the factors of marine health, safety and security.4- Diving centers do not implement adequate rehabilitation programs for beginners divers.5- Marine safety, health and safety equipment (pressure room - first aid kit - oxygen cylinders - diving flags - emergency assistance and emergency communication) is not widely available on the ship or diving centers.
\end{abstract}

\section{Introduction and Research Problem:}

Diving is one of the recreational and utilitarian water sports, which made it spread in all coasts of the world, which may gain its practitioner characteristics that distinguish it from other sports practitioners, as well as the importance of diving in various other areas of life such as sports, military, economic, discoveries, environmental pollution, the scientific and geographical field, and the study of marine science and geology Zoology, foreign tourism and domestic tourism, which are an important source of income in the Arab Republic of Egypt, as well as an experience of excitement and adventure in the water space and an underwater world, and get to know various 
types of amazing life and discover A world of amazing beauty in the oceans, seas and rivers. When human Slink in water moves from the center antenna body Almighty God to live to the center of a completely different aqueous.

The researcher agrees with what Magdy Mohamed Abu Zaid (2012) also adds that diving is one of the popular sporting activities that have caught the attention of physicians and physiologists to learn the physiological and health responses resulting from practicing this unique sport, as diving is an unconventional activity compared to other water sports activities, As it is a unique environment and it is the depths of water that require a person to be supplied with more oxygen and air while staying underwater for specific periods of time as it is affected by many direct and indirect pressures, so it is necessary to have health and physical conditions and requirements When the practice of underwater diving, where any mistake or ignorance of the rules of diving may lead to the occurrence of serious diseases or cast man died. $(3: 186,187)$

Ahmed Sabry Hegazy (2014) adds that the noticeable increase in the number of recreational diving centers requires serious scientific codified attention to the various aspects of diving sports, because of the risks of accidents and diseases surrounding human practice, due to lack of experience and failure to absorb the requirements of integrated training, some divers are exposed to Depths of water for problems in dealing with the different pressures, temperatures, and changes that occur in the vital processes of the body, for example the skeleton, muscles, nervous system, respiratory system, as well as the ear and sinuses, as well as facing upset problems Use auxiliary devices to supply the air needed to breathe in various depths. (1:3)

Accordingly, the problem of the study stems from the importance of studying diseases, injuries and accidents related to the most prevalent diving in diving in the Arab Republic of Egypt, which may lead to death in most cases, and touching on setting scientific standards to avoid accidents, diseases and injuries of diving to know its relationship with marine health and safety of divers, and knowledge of Prevention methods and methods to avoid various diving accidents, diseases and injuries, and this is what the researcher called to address the subject of the research in order to improve the health and safety of marine divers and reduce the occurrence of diving diseases, accidents and injuries in the Arab Republic of Egypt and its reflection on The performance of scuba divers in the field of diving, as important requirements in scuba diving of all kinds and fields.

\section{Research Objectives:}

1- Knowing the diving accidents, diseases and injuries prevailing in the Arab Republic of Egypt and limiting their spread and prevention.

2-Learn about the causes of diving accidents, diseases and injuries and work to avoid them.

3- Defining the scientific methods and means to avoid diving accidents, diseases and injuries.

4- Setting scientific standards to improve marine health and the safety of divers.

5- Learn about diving accidents and diseases spread in Australia, the leader in diving.

\section{Research questions:}

- What are the diseases, accidents and injuries related to scuba diving in the Arab Republic of Egypt?

-Are there any physical, professional and medical conditions and requirements for diving? Do diving centers observe these conditions?

-Do maritime safety, health and safety factors apply to diving centers in the Arab Republic of Egypt?

-Are there significant statistically significant differences between the extent to which maritime safety, health and safety factors are applied, diving accidents, diseases and injuries? 
-Do studying the numbers of diving accidents and their causes will lead to the development of maritime safety, health and safety factors and training methods used in order to reduce diving accidents, diseases and injuries?

\section{Research Methodology}

\section{The Research Approach}

To achieve the research objectives and in line with the nature of its variables, the researcher used the descriptive, analytical approach.

\section{Research Sample}

150 recreational, commercial and professional diver and diving training students at the Faculty of Physical Education, Alexandria University, were randomly selected to answer the questionnaire. Table (1) shows the relative distribution of the research sample from the total of the research sample. $\mathbf{N}=\mathbf{1 5 0}$

\begin{tabular}{|c|c|c|c|c|}
\hline \multicolumn{2}{|r|}{ Sample } & \multicolumn{2}{|c|}{ The number } & $\%$ percentage \\
\hline \multicolumn{2}{|c|}{ Professional divers } & 10 & & $\% 6.67$ \\
\hline \multicolumn{2}{|c|}{ Commercial diver } & 24 & & $\% 16.00$ \\
\hline \multicolumn{2}{|c|}{ A student specializing in diving training } & 20 & & $\% 13.33$ \\
\hline \multicolumn{2}{|c|}{ Entertainment diver } & 96 & & $\% 64.00$ \\
\hline \multicolumn{2}{|l|}{ Total } & 150 & & $\% 100$ \\
\hline \multicolumn{5}{|c|}{ Percentage } \\
\hline $6.67 \%$ & $16.00 \%$ & $13.33 \%$ & & \\
\hline $\begin{array}{c}\text { Professional } \\
\text { divers }\end{array}$ & $\begin{array}{c}\text { Commercial } \\
\text { diver }\end{array}$ & $\begin{array}{l}\text { A student } \\
\text { specializing in } \\
\text { diving training }\end{array}$ & \multicolumn{2}{|c|}{$\begin{array}{l}\text { Entertainment } \\
\text { diver }\end{array}$} \\
\hline
\end{tabular}

A graph (1) shows the percentage of the research sample from the total of the research sample.

Table (2) the statistical significance of the research sample in the variables of the age group, years of experience, and the number of dives in the research sample $\mathrm{N}=150$. 


\begin{tabular}{r|r|r|r|r||r||r}
\hline \hline Statistical & measuring & SM & Mediator & $\begin{array}{r}\text { standar } \\
\text { deviatic }\end{array}$ & $\begin{array}{r}\text { Coefficien } \\
\text { torsion }\end{array}$ & $\begin{array}{c}\text { Flatness } \\
\text { coefficient }\end{array}$ \\
\hline Age group & No. & 28.9 & 26.00 & 9.20 & 1.65 & 2.03 \\
\hline \hline Years of Experience & Year & 8.48 & 7.00 & 5.14 & 1.31 & 1.27 \\
\hline \hline Number of submarine & No. & 1159. & 180.00 & 2063.6 & 2.59 & 6.65 \\
\hline \hline
\end{tabular}

\section{Research tools}

Data was collected through questionnaires and personal interviews with experts in the field of diving, a sample of professional divers, divers working in the field of commercial diving, divers working in the field of recreational diving, and students of diving specialization in the Faculty of Physical Education for Boys, University of Alexandria.

\section{Statistical Methods Used}

In light of the research variables and in order to achieve its goals, the researcher found statistical treatments using the SPSS version 20 program, as follows:

-SMA. Mean

- Stander Deviation.

- Median Mediator.

- Skewness.

- Flatulence coefficient. Kurtosis-

- Percentage \%.

-Chi square.

\section{Results and Discussions}

\section{First Presentation and Discussion of Questions Results}

The First Questions states that:

- What are the diseases, accidents and injuries related to scuba diving in the Arab Republic of Egypt?

For answering this question:

Table (3) shows the frequency, percentage, and Kay range for the most common diseases, accidents and diving injuries in the Arab Republic of Egypt. $\quad \mathrm{N}=150$

\begin{tabular}{|c|c|c|c|c|c|c|}
\hline \multirow{2}{*}{ No. } & \multirow{2}{*}{ Statistical } & \multicolumn{2}{|c|}{ Agree } & \multicolumn{2}{|c|}{ Disagree } & \multirow{2}{*}{ Chi square } \\
\hline & & Repetitid & $\%$ Percen & Repetitid & Percentag & \\
\hline 1 & Hypoxia & 1 & $\% 1$ & 149 & $\% 99$ & $* 146.03$ \\
\hline 2 & Oxygen poisoning & 0 & $\% 0$ & 150 & $\% 100$ & ---- \\
\hline 3 & Suffocation & 1 & $\% 1$ & 149 & $\% 99$ & $* 146.03$ \\
\hline 4 & Inhalation of salt water & 17 & $\% 11$ & 133 & $\% 89$ & *89.71 \\
\hline
\end{tabular}




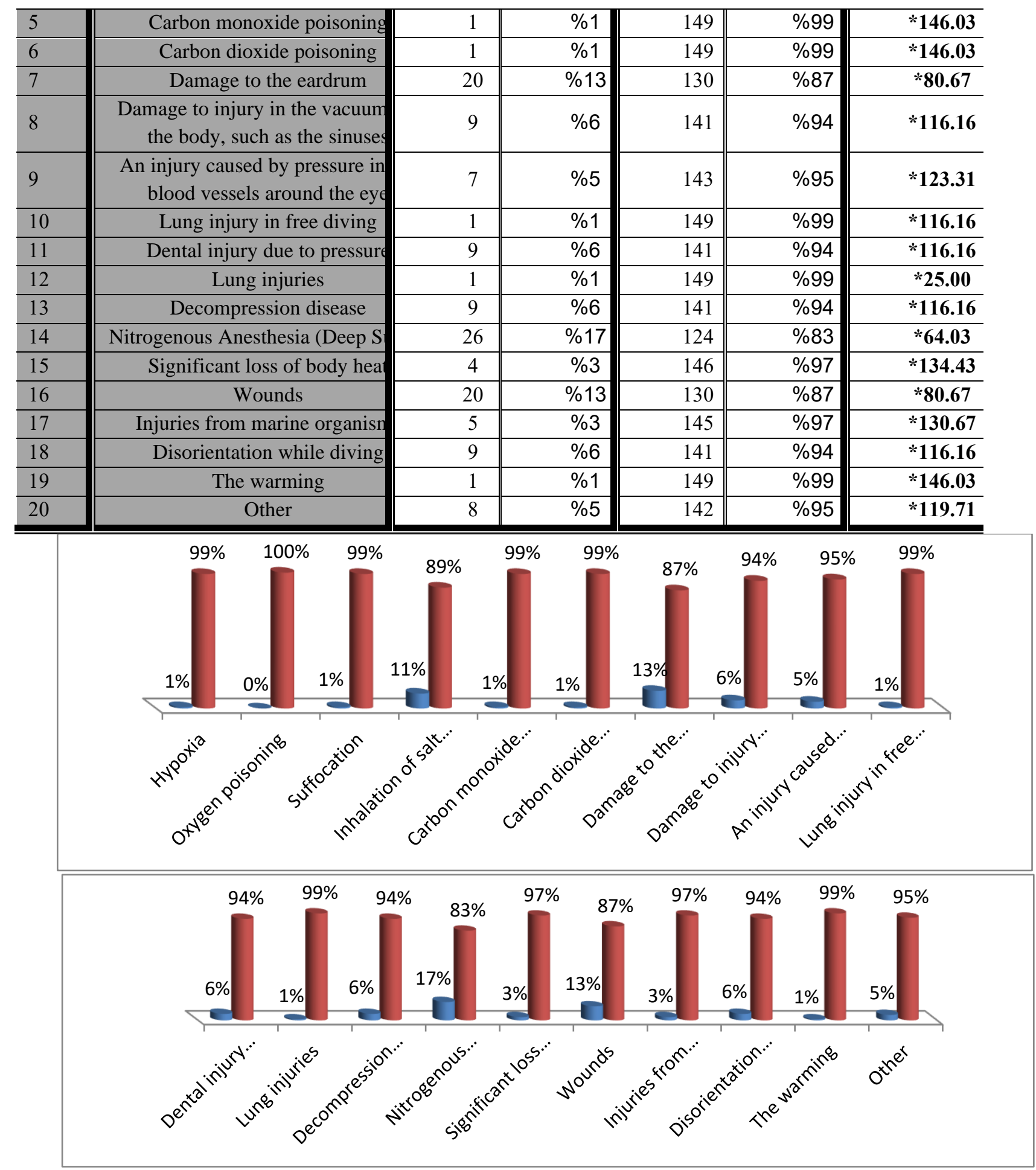

Graph (2) shows the percentage of diseases, accidents and diving injuries most common in the Arab Republic of Egypt.

In light of this, the researcher attributes the increase in the percentage of nitrogenic anesthesia (deep sugar) $17 \%$, to the fact that this disease often comes due to diving at great depths exceeding 28 meters.

In line with the study of Mohamed Youssef ElBaradei (2016) that when a diver reaches a depth of 30 meters, the partial pressure of the nitrogen gas formed inside the blood begins to cause anesthesia effect on the diver's mind as the blood transports nitrogen to the brain cells that are affected by it and the effect of nitrogen on the diver's mind By losing control of his behavior and 
focus, and symptoms increase as depth increases, until the diver loses his senses, and this disease can be avoided by diving going up to a lower depth to eliminate the disease directly. If these effects do not go away, the diver can get out of the water directly in order to avoid the dangers of this disease. (5:32).

The researcher believes that the percentage of damage to an eardrum injury $13 \%$ is due to a failure to equalize the ear by the diver due to the lack of experience from the diver.

This is consistent with Braun et al. (2018) in a study that explains a large number and attempts to explore the main risks of diving accidents that resulted in ear injuries $(69.0 \%)$, as well as cardiovascular complications (13.8\%), and pressure reduction incidents $(20.7 \%)$ in Often during diving underwater in Switzerland. (10)

This is also consistent with what Ahmed Sabry Hegazy (2014) mentioned that frequent diving at short periods of time may cause damage to the ear structure, and this diver did not notice if the period between each dive to the other exceeded approximately 11 hours. (1: 69).

The researcher also attributes the percentage of wounds, $13 \%$, to an error in equipment due to diving without wearing a full suit, gloves and diving shoes.

These results are consistent with walla Wael Hafez's loyalty (2008) that wounds often come from coral reefs, shipwrecks, rocks, and areas with strong currents of high risk, so a diver should avoid touching anything that might lead to wounds. (7)

The percentage of saline inhalation came $11 \%$, as a result of a mistake by the diver or a failure in the equipment represented by a malfunction in the air valve demand valve, which leads to inhalation of a little salt water mist, which leads to irritation in the lung.

In line with Carl Edmonds et al (2013), inhalation of salt water leads to a pulmonary disorder called ascites among divers. (11)

This is consistent with the results of the Lawrence et al (2018) study that among the causes of deaths in diving conditions in Australia are drowning due to problems related to equipment maintenance, diving alone, lack of oxygen to inhale large quantities of salt water, poor organization and good planning of diving, as well as lack of good supervision By diving centers. (14)

The researcher also finds that the percentage of injury to the teeth due to pressure $6 \%$ is due to a previous injury to the diver's teeth, such as decay or bad fillings.

This is consistent with Zadik et al. (2011) indicated that the diver must perform a periodic examination of his teeth and follow up fully aware of the effect of pressure on the body, research the factors causing dental injuries and take preventive measures for them. (18)

With regard to the percentage of damage to injury in the vacuums of the body, such as the sinuses, $6 \%$, as a result of an error and lack of experience by the diver and diving during a cold or a nasal allergy.

This is consistent with the study of Ahmed Sabry Hegazy (2014) that injury to the sinuses during diving causes severe pain to the diver and may lead to an explosion of the blood vessels of the nose. Bleeding in the nose often occurs, and occurs as a result of the difference in pressure between the sinuses and the external pressure. $(1: 69,70)$

The researcher also believes that the percentage of disorientation during diving is $6 \%$, due to a mistake by the diver, his lack of experience and the failure to use diving maps and navigational devices.

Bosco et al. (2020) agree that road loss may occur during diving as a result of environmental factors such as currents and high waves that led to his distancing from the colleague, the diver may not reach the shore and may be subject to drought, air permeability and death. (9) The researcher attributes the percentage of injury resulting from pressure in the blood vessels around the eye, $5 \%$, due to the lack of experience from the diver or a failure in the equipment that 
led to the inability to equalize the pressure inside the face mask.

In line with Lundel et al. (2020) study, pressure in the blood vessels around the eye leads to bleeding beneath the conjunctiva, which is caused by an imbalance of pressure inside the face mask, which increases the air pressure inside the face mask. (16)

In light of this, the researcher returns that previous accidents and injuries are among the most common and widespread diseases in various diving fields due to the difficult nature of diving performance and the extremely dangerous marine environment. These diseases and accidents may lead to complete disability or the loss of a diver's life.

This is consistent with the study of Fock et al. (2013) where a single review of diving-related deaths reported in Australia in 2009 was found, as it was found that the causes of many deaths in this series are pre-existing medical conditions, diving alone, and hypoxia in The body, and the lack of good supervision of divers by diving institutions. (13)

The Second Questions states that:

-Are there any physical, professional and medical conditions and requirements for diving? Do diving centers observe these conditions?

For answering this question:

Table (4) shows the frequency, percentage, and Kay square for the most prevalent causes of diving diseases, accidents and injuries. $\quad \mathrm{N}=\mathbf{1 5 0}$

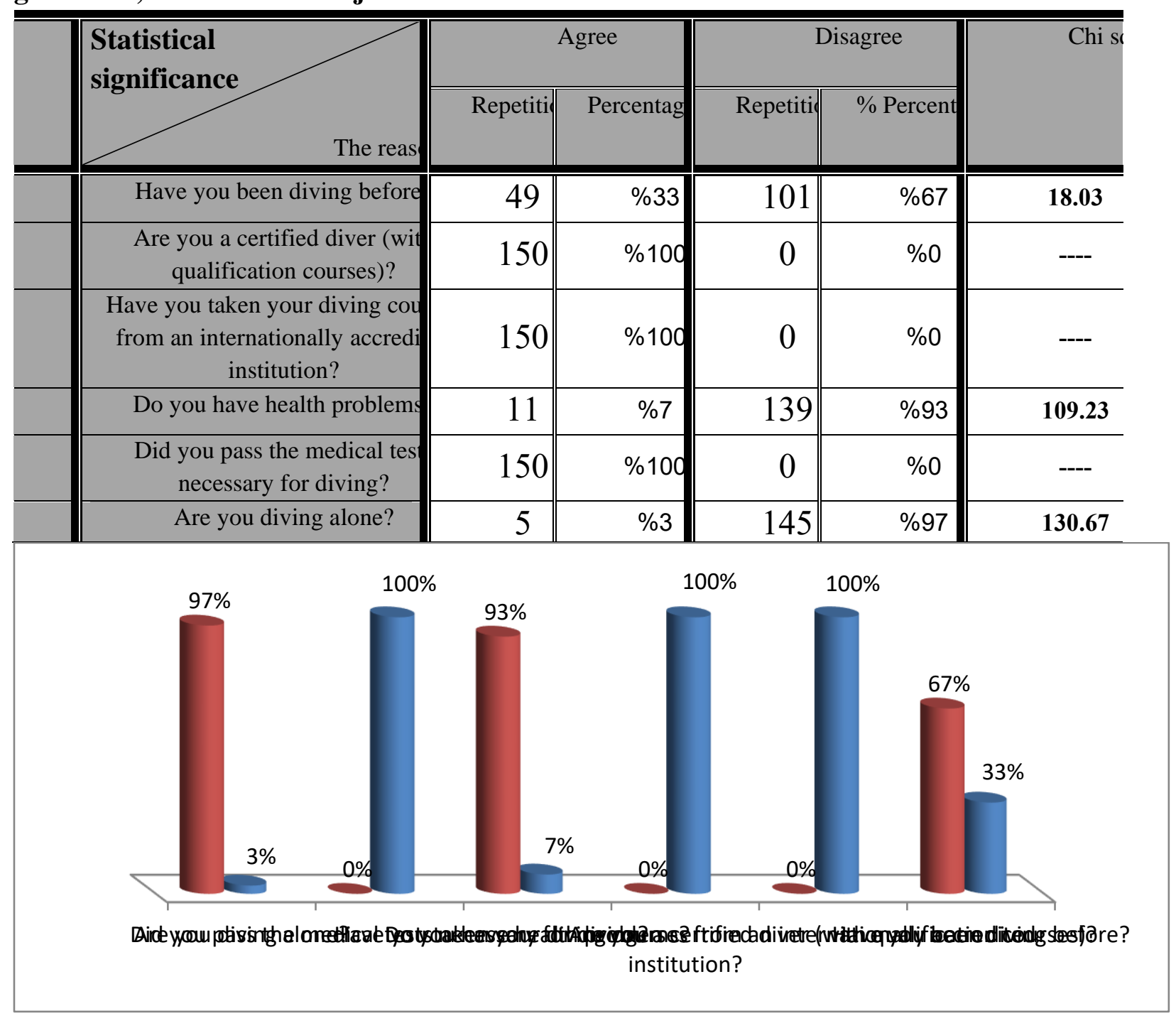


The researcher believes that one of the most common causes that lead to accidents, diseases and injuries of diving are the medical history of divers and the lack of medical examinations before performing diving and insufficient rehabilitation for beginners divers, an error by the diver and lack of experience from him, neglecting examination and periodic maintenance of diving equipment.

In line with Ascencio et al. (2019) in a study to analyze diving accidents and injuries for 20 years in Australia, it was found that the most important factors causing most of the incidents identified were the pre-existing health conditions for divers, the experience of diving alone, lack of good training, and inadequate rehabilitation for beginners divers, Equipment failure (condition and maintenance). (8)

In light of this, the researcher attributes the increase in the percentage of you are a certified diver (holds qualifying courses?) $100 \%$ Yes, and the percentage of you got your diving courses from an internationally accredited institution $100 \%$ Yes, to that it is one of the most important conditions and requirements for performing diving The diver gets accredited training courses from various international diving federations.

Mohamed Mahmoud Hussein (2016) indicates that there are multiple diving organizations in the world in general and in the Arab Republic of Egypt in particular, but they agree to try to achieve one goal is to spread and educate this sport, and these organizations are CMAS, BADI, NAUI, BSAC, YMCA, IDIA, NASDS, SSI, PDIC, NASE, WASI. (4: 35,39)

The researcher returns the percentage of whether she succeeded in passing the necessary medical tests for diving. $100 \%$ Yes, until one of the important conditions or requirements for diving is that the diver performs checks and medical checks before diving.

This is consistent with Muhammad Muhammad Suleiman (2017) that diving requires physical conditions and requirements for the diver to perform the tasks assigned to them safely in the depth of the aqueous medium, in addition to the ability of its members to adapt to the conditions of increasing pressure under the water during the use of breathing devices, the most important of which are tests on the efficiency of the nose and ear Larynx to ensure the ability of these organs to perform its functions efficiently and free from any acute or chronic injuries, diseases or infections. $(6: 32)$

The researcher also returns the percentage of what is the environment in which diving is practiced? $100 \%$ of seashore, to the fact that the environment is an important factor affecting the diver during the practice of diving.

In line with Ahmed Sabri Hegazy (2014) that almost three quarters of the earth is covered with water in the form of seas, rivers, oceans, lakes and other water bodies, and this environment differs within it from those known to humans as it has a special physical nature. (1:38) As the researcher returns the percentage of what is your dive history? $100 \%$ from 3 years to 25 years, and the percentage of what type of diving activity is practiced by $77 \%$ recreational diver, $16 \%$ commercial diver, $7 \%$ professional diver that the purposes and types of diving are many and multiple and differ in terms of the nature of the performance of each type.

Consistent with Karim Ahmed Shehata (2012), diving has many purposes and is divided according to the aim of diving and the tools used and depth as well as the desired tasks of the diver which includes commercial diving, recreational diving, diving for marine rescue, military diving, diving for services Ships, scientific diving. $(2: 3,6)$

And the researcher believes that the percentage of he had a diving injury before? $33 \%$ Yes, due to the fact that diving is a sport of a dangerous nature, as the diver faces a lot of risks while diving under water.

This concurs with the results of Mohamed Youssef ElBaradei (2016) study that the diseases and accidents resulting from the practice of diving are many and many that affect many divers due to the difficult nature of their work, as well as their stay at the bottom for very long periods, and these diseases may lead to the diver being permanently injured or The diver may lose his life. 
It is also consistent with the results of the study of Casadesús et al. (2019) that after analyzing diving accidents prevalent in Spain, it was found that the most common and frequent incidents and injuries identified by divers are rapid ascending, and cardiac accidents such as myocardial ischemia, asphyxia, lung expansion, and exerted excess effort, Panic, buoyancy problems, and confusion, which can often lead to drowning and death. (12)

The researcher also believes that the percentage of do you have health problems? $7 \%$ Yes, due to the diver's medical history being closely related to his risk of diving diseases, accidents and injuries.

This is in line with the findings of the Shreeves and others study (2018), where it was found that the previous medical condition of divers corresponds to the probability of death due to divers suffering from chronic diseases of the heart and lungs, as well as the lack of quality training before diving is associated with more than half of the deaths of divers in North America. (17) Also, consistent with those results, what was referred to by Lippmann (2019) in a study to determine the underlying factors and risks associated with diving sport, the application of appropriate maritime safety and security factors and knowledge of diving deaths in Australia, it was found that one of the main causes of diving accidents that lead to death is often represented by human factors such as Chronic health conditions, inexperience, poor planning for diving and poor skills for junior divers. (15)

\section{Conclusions}

In light of the research objectives, hypotheses, the nature of its variables and the results of statistical treatments, the researcher has been able to reach the following conclusions:

1- It was found that the most common diseases, accidents and injuries related to diving are (nitrogen narcosis), (damage to an eardrum), (wounds), (inhalation of salty water), (injury to the teeth due to pressure), (damage to injury in the body's spaces such as sinuses Nasal), (disorientation during diving), (injury caused by pressure in the blood vessels around the eye) [The percentages were, respectively, 17\%, 13\%, 13\%, 11\%, 6\%, 6\%, 6\%, 5\%.

2 - The reasons for the occurrence of many diving injuries and accidents that were addressed in the study were identified, and the knowledge of how to prevent and treat them and reduce their incidence rates was determined.

3- The diving centers do not fully apply the factors of marine health, safety and security.

4- Diving centers do not implement adequate rehabilitation programs for beginners divers.

5- Marine safety, health and safety equipment (pressure room - first aid kit - oxygen cylinders diving flags - emergency assistance and emergency communication) is not widely available on the ship or diving centers.

\section{Recommendations}

In light of the findings of this study, the researcher recommends the following:

* Take precautionary measures to avoid divers and the occurrence of various diving diseases, accidents and injuries, which are represented in the following:

1- Conducting medical examinations and examinations before diving, periodically, through recognized medical institutions.

2- Good training and qualification for beginners divers working in the field of diving by certified diving institutions.

3- Selecting the appropriate diving equipment, and performing regular maintenance for it continuously.

4- Avoid diving alone, and diving with the colleague always.

5- Not to exceed the permissible depths in order to preserve your safety and that of your colleague.

6- Commitment to safety, health and safety factors by diving facilities and divers.

7- The necessity of using pressure rooms and depth medicine in treating accidents, diseases and injuries related to diving. 


\section{References}

\section{Arabic References}

1 Ahmed Sabry Mohamed Suleiman

2 Karim Ahmed Ibrahim (2012): Shehata

Modern training methods for diving, swimming and people with special needs, Faculty of Physical Education, Alexandria University.

Mohamed Mahmoud Hussein Hussein

(2016):

Physical, Physical, and Physiological Determinants of Selection of Dive Instructors, Master Thesis, Unpublished, Faculty of Physical Education for Boys, Minia University.

$5 \quad$ MohamedYoussef

Mohamed ElBaradei

(2016): Comparing the effect of terrestrial and aquatic aerobic training on developing the efficiency of the periodic respiratory system work for divers, Master Thesis, unpublished, Faculty of Physical Education for Boys, University of Alexandria.

6 Muhammad Muhammad Sulayman

$7 \quad$ Walaa Wael Hafez

(2008): The Book of Diving, Dar Al-Maaref, Alexandria.

\section{English References}

8

Ascencio-Lane JC1,2, Smart D1,3, Lippmann J4,5.
A 20-year analysis of compressed gas diving-related deaths in Tasmania, Australia.

Arterial blood gases in divers at surface after prolonged breathhold. 
10 Braun CT1,2, Kollow P1, Kollow G2, KlukowskaRötzler J1, Schedler O2, Lehmann B1, Exadaktylos AK1.

11 Carl Edmonds.

12 Casadesús JM1,2,3,4, Aguirre F5, Carrera A6,7,8, Boadas-Vaello P6,7,8, Serrando MT8,9, Reina F6,7,8.

13 Fock A3, Lippmann J1, Lawrence C2, Wodak T4, Jamieson S5.

14 Lawrence C4,Lippmann $\mathrm{J1,2,3}$, Fock A5, Jamieson S2.

$15 \quad$ Lippmann J1,2,3.

(2019): Snorkelling and breath-hold diving fatalities in Australia, 2001 to

16 Lundell RV1,2, RäisänenSokolowski AK3,4, Wuorimaa TK5, Ojanen T6, Parkkola KI7,8.

17 Shreeves K1, Buzzacott P, Hornsby A, Caney M.

18 Zadik Y., Drucker S. 2013. Demographics, characteristics and chain of events.

(2018): [Diving Accidents in Lakes - a Retrospective Study of a Level-1 Emergency Centre in Switzerland].

:(2013) Diving Medicine for scuba divers 5th edition. Manly, NSW, 2095 Australia.

(2019): Diving-related fatalities: multidisciplinary, experience-based investigation.

(2013): Provisional report on diving-related fatalities in Australian waters 2009.

(2018): Provisional report on diving-related fatalities in Australian waters in 2012.

(2020): Diving in the Arctic: Cold Water Immersion's Effects on Heart Rate Variability in Navy Divers.

(2018): Violations of safe diving practices among 122 diver fatalities.

(2011): Diving dentistry: a review of the dental implications of scuba diving. Australian Dental Journal. 